\title{
INTEGRATED AUTOMOTIVE MANUFACTURING SUPPLY
}

\author{
P.J.S. van Dyk ${ }^{1}$, J.J. Strasheim ${ }^{2}$ and C. de W. Van Schoor ${ }^{3}$ \\ ${ }^{2,3}$ Department of Industrial and Systems Engineering \\ University of Pretoria, South Africa \\ 2johan.strasheim@up.ac.za , ${ }^{3}$ chrisvs@supremespring.co.za
}

\begin{abstract}
Supply planning and traffic flow planning are major activities in the automotive manufacturing environment worldwide. Traditionally, the impact of supply planning strategies on plant traffic is rarely considered. This paper describes the development of a Decision Support System (DSS) that will assist automotive manufacturers to analyse the effect of supply planning decisions on plant traffic during the supply planning phase of their logistics planning process. In essence, this DSS consists of a Supply Medium Decision Support Tool (SMDST) (an interactive MS-Excel model with Visual Basic interfacing) and a traffic flow simulation model tool (using eMPlant simulation software).
\end{abstract}

\section{OPSOMMING}

Verskaffingsbeplanning en verkeersvloeibeplanning is belangrike aktiwiteite in die motorvervaardigingsbedryf wêreldwyd. Tradisioneel word die uitwerking van verskaffings-beplanningsstrategië op aanlegverkeer selde in ag geneem. Hierdie artikel beskryf die ontwikkeling van 'n Besluitnemings Ondersteuningstelsel (DSS) wat motorvervaardigers sal ondersteun in die analise van die effek van verskaffingsbeplanningbesluite op aanlegverkeer tydens die verskaffingsbeplanningsfase van hulle logistieke beplanningsproses. Hierdie DSS bestaan hoofsaaklik uit 'n Verskaffings-vervoermiddel Besluitnemingshulpmiddel (SMDST) ('n interaktiewe MS-Excel model met “Visual Basic" koppelling) asook 'n simulasiemodel van verkeersvloei (met eM-Plant simulasiesagteware).

\footnotetext{
${ }^{1}$ This author was enrolled for the M Eng (Industrial Engineering) at the Department of Industrial and Systems Engineering, University of Pretoria
} 


\section{INTRODUCTION}

Supply planning and traffic flow planning are major activities in the automotive manufacturing environment worldwide. Supply planning directly influences the traffic within a manufacturing plant. The impact of supply planning strategies like Just-in-Time, Just-in-Sequence and Direct Supply on plant traffic is rarely considered, as supply and traffic flow planning are traditionally seen as separate activities.

BMW is one of the leading international automotive manufacturers. BMW Plant 9 in Rosslyn, South Africa, is planning to switch production from the E46 (current 3series) model to the E90 (new 3-series) model in 2005. Logistic supply planning for the new E90 model was recently started and is still at a stage where it is relatively open and flexible to justifiable suggested changes.

\section{PROBLEM STATEMENT}

BMW SA and other automotive manufacturers are facing various specific problems relating to supply and traffic flow planning. One of these problems is in selecting the best supplier transportation medium among various alternatives for the supply of each part family, taking into account the effects on plant traffic. Several variables have to be considered during this decision making process, and no decision support tool exists at present to assist during this process.

Another problem faced by automotive manufacturers lies in assessing the impact of physical relocation decisions on plant traffic. Several proposed plant layout changes and changes to the location of supplier delivery points are considered for BMW Plant 9 in Rosslyn. These proposed changes will imply large relocation expenses, and will inevitably have a major impact on the traffic flow within the plant. The consequent impact of these proposed layout changes has to be investigated, analysed and compared.

\section{DEVELOPING A DECISION SUPPORT SYSTEM}

In response to this problem, tools have been developed that will assist automotive manufacturers to analyse the effect of supply planning decisions on plant traffic during the supply planning phase of their logistics planning process. Even though these tools can function independently, their real value is only realised once they are used in conjunction with one another as a Decision Support System (DSS). "Decision support systems couple the intellectual resources of individuals with the capabilities of the computer to improve the quality of decisions. It is a computer based support system for management decision makers who deal with semistructured problems"[12]. DSS are used in making decisions where sufficient structure exists for computer and analytical aids to be of value but where human judgements are essential. The aim when developing a DSS is to create a supportive tool for management use that does not attempt to automate the decision process, predefine objectives, or impose solutions. It should serve as an extension of the user's problem solving capabilities. In essence, the DSS developed during this 
project consists of a Supply Medium Decision Support Tool (SMDST) and a Traffic Flow Simulation Model tool.

\subsection{Supply medium decision support tool}

\section{User requirements specification}

The tool should:

- Be fast, efficient and user friendly to implement and use

- Incorporate all variables influencing the supply medium selection process

- Be easily integrated with existing software and applications in use by automotive manufacturers

- Be flexible enough to allow for easy updating or addition of data

- Calculate and compare the number of deliveries required per day for all supplier deliveries for use as input to a traffic flow simulation model

- Have a User Manual assisting the implementation and use of the tool

- Be available in English and German, as it will be distributed to and used by automotive manufacturers in South Africa and Germany

\section{Tool development}

The Supply Medium Decision Support Tool (SMDST) developed is an interactive MS-Excel model with Visual Basic interfacing. The tool was developed as far as possible to satisfy the abovementioned user requirements. The developed tool consists of three main components, namely input data sheets, main street and Visual Basic (VBA) module.

\section{Input data sheets}

These three sheets (namely the Boundary Conditions-, Part Families- and Delivery Cycle Times sheet) contain all the data required to perform the calculations, and can be viewed and updated conveniently while using the tool. This includes:

- Truck information

- Truck types available

- Dimensions of loading area for each truck type

- Load restrictions for each truck type

- Cost per day for each truck type

- Supplier information

- All suppliers

- Delivery cycle time for each supplier

- Part family information

- All parts delivered

- Part weight

- Parts required per final product 
- Stillage dimensions

- Stillage weight

- Parts per stillage

\section{Main sheet}

This sheet serves as the main user interface. Here the user can set the following criteria in the tool:

- Part family to be analysed: selected from a drop-down list on the main sheet.

- Offloading device: the user can specify whether a forklift or stacker will be used to offload the parts from the delivery vehicle. This has an influence on the maximum height that parts can be stacked on the delivery vehicle in later calculations.

- Manner of offloading: the user can specify whether the parts will be offloaded from the side or back of the delivery vehicle. This has an influence on the way the parts will be packed on the delivery vehicle.

- Stackability: the user can specify whether the stillages may be stacked on top of one another when packed on the delivery vehicle.

\section{Visual Basic module}

This module contains the code for all the calculations made by the tool. All necessary data are extracted from the input data sheets and main sheet into the VBA module, calculations are made and results are displayed for the user in the main sheet.

Following the user requirements, all calculations enabling the tool were translated from MS-Excel formulas into Visual Basic code in order for it to be easily integrated with existing software and applications in use by automotive manufacturers. ${ }^{2}$ A user manual has been made available to guide the user during the set-up and use of the tool. The SMDST and user manual have been made available in English and German.

Variables have been declared in VBA to be used during calculations. All variables have been declared as one of the following four types:

- Integer: a whole number (not a fractional number) that can be positive, negative, or zero

- Double: also known as type "Real”, which can be any value (whole or fractional) in the infinitely divisible range of values between positive and negative infinity

- String: also known as type "text", containing any combination of text

- Boolean: equal to one of two values: true or false

The following is a list of variables that have been declared in VBA and a description of the logic behind the VBA calculations. Values are read from the main- and input

\footnotetext{
${ }^{2}$ EM-Planner is a good example of such an application. It's "API" function allows for easy integration of VBA programs into its models. Refer to www.tecnomatix.com for more on this application.
} 
data sheets and the appropriate variables (in VBA) set equal to these values each time any variable is changed in the input data sheets or main sheet by the user.

- products_produced_per_day (as type Integer): the number of cars produced in the plant per day, value read from Main sheet

- parts_per_Product (as type Integer): the number of the part of the specific part family required per car produced, value read from Part Families sheet

- efficiency (as type Double): measure of the usage efficiency of the specific part family, calculated as: $100 \%$ - percentage (\%) scrapped, value read from Part Families sheet

- parts_per_Stillage (as type Integer): the number of parts that are packed in a single stillage, value read from Part Families sheet

- partWeight (as type Double): the weight of a single part of the specific part family, value read from Part Families sheet

- lengthStillage (as type Double): the length of the stillage used for the specific part family, value read from Part Families sheet

- widthStillage (as type Double): the width of the stillage used for the specific part family, value read from Part Families sheet

- heightStillage (as type Double): the height of the stillage used for the specific part family, value read from Part Families sheet

- offloadingDevice (as type String): an indication of whether a forklift or stacker will be used to offload the stillages from the delivery vehicle, read from Main sheet

- offloadingManner (as type String): an indication of whether the stillages will be offloaded from the side or back of the delivery vehicle, read from Main sheet

- stackability (as type Boolean): an indication of whether the stillages may be stacked on top of one another or not when packed on the delivery vehicle, read from Main sheet

- maxWeightVehicle (as type Double): the load weight restriction of the vehicle under consideration, value read from Boundary Conditions sheet

- maxWeightTrailer (as type Double): the load weight restriction of the vehicle's trailer under consideration, value read from Boundary Conditions sheet

- stillageWeight (as type Double): the weight of the stillage used for the specific part family, value read from Part Families sheet

- lengthVehicle (as type Double): the length of the vehicle's carrying space ${ }^{3}$ under consideration, value read from Boundary Conditions sheet

- widthVehicle (as type Double): the width of the vehicle's carrying space under consideration, value read from Boundary Conditions sheet

- heightVehicle (as type Double): the height of the vehicle's carrying space under consideration, value read from Boundary Conditions sheet

- lengthTrailer (as type Double): the length of the trailer's carrying space under consideration, value read from Boundary Conditions sheet

- widthTrailer (as type Double): the width of the trailer's carrying space under consideration, value read from Boundary Conditions sheet

\footnotetext{
${ }^{3}$ Defined as the space that can be utilised for packing stillages in / on the vehicle, and not the dimensions of the entire vehicle
} 
- heightTrailer (as type Double): the height of the trailer's carrying space under consideration, value read from Boundary Conditions sheet

- boundaryDistanceRight (as type Double): the boundary distance ${ }^{4}$ on the vehicle's right side, value read from Boundary Conditions sheet

- boundaryDistanceLeft (as type Double): the boundary distance on the vehicle's left side, value read from Boundary Conditions sheet

- boundaryDistanceFront (as type Double): the boundary distance on the vehicle's front, value read from Boundary Conditions sheet

- boundaryDistanceBack (as type Double): the boundary distance on the vehicle's back, value read from Boundary Conditions sheet

- boundaryDistanceTop (as type Double): the boundary distance on the vehicle's top, value read from Boundary Conditions sheet

With these variables set, VBA continues by making the following calculations for the remaining variables:

- Parts_per_day (as type Double): the number of parts of the specific part family required per day, calculated from:

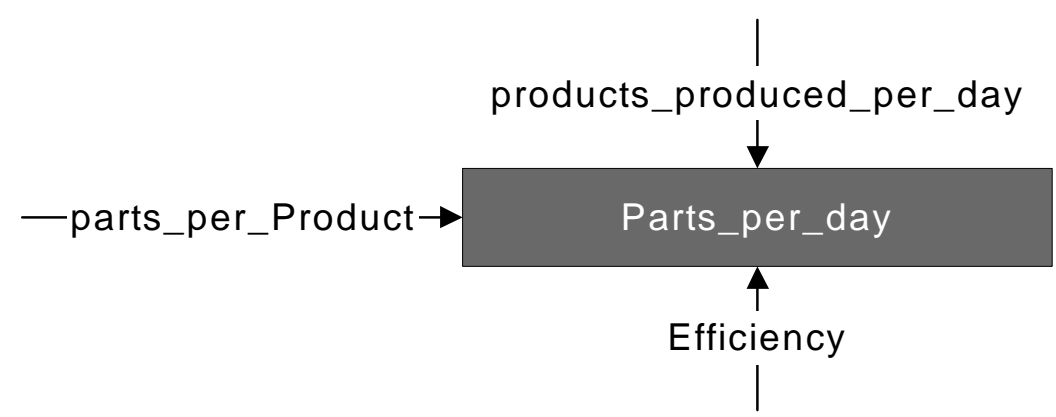

- Stillages_per_day (as type Integer): the number of stillages of the specific part family required per day, calculated from:

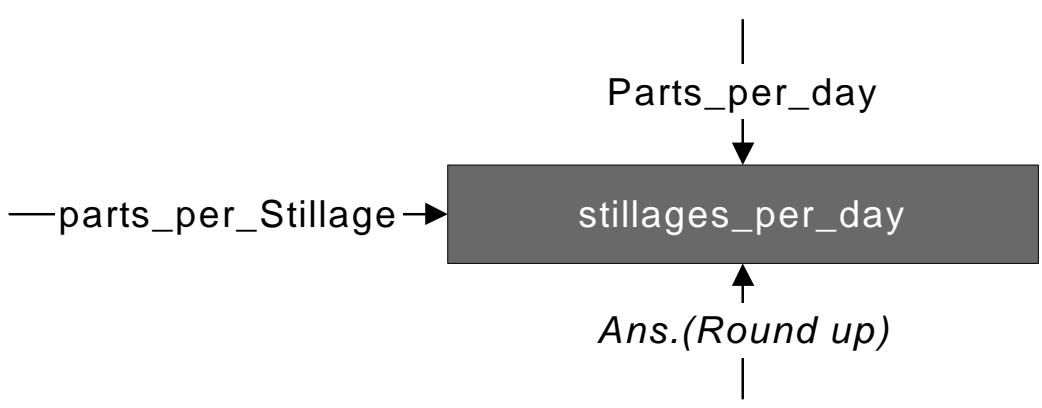

- stillage_with_Parts_Weight (as type Double): the weight of a full stillage (stillage carrying parts), calculated from:

\footnotetext{
${ }^{4}$ Defined as the distance on a specific side of a vehicle than cannot be utilised as carrying space, due to restrictions of the offloading device used
} 


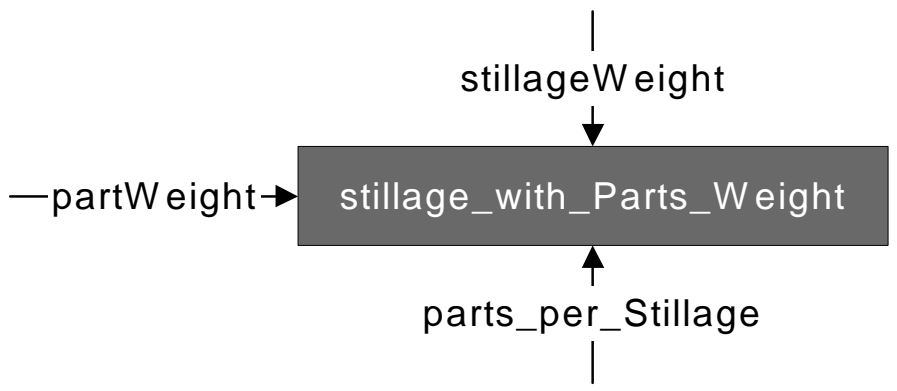

- NumberStillagesPerVehicle_Volume (as type Integer): the maximum number of stillages of a specific part family that fits into the vehicle's carrying space, calculated from:

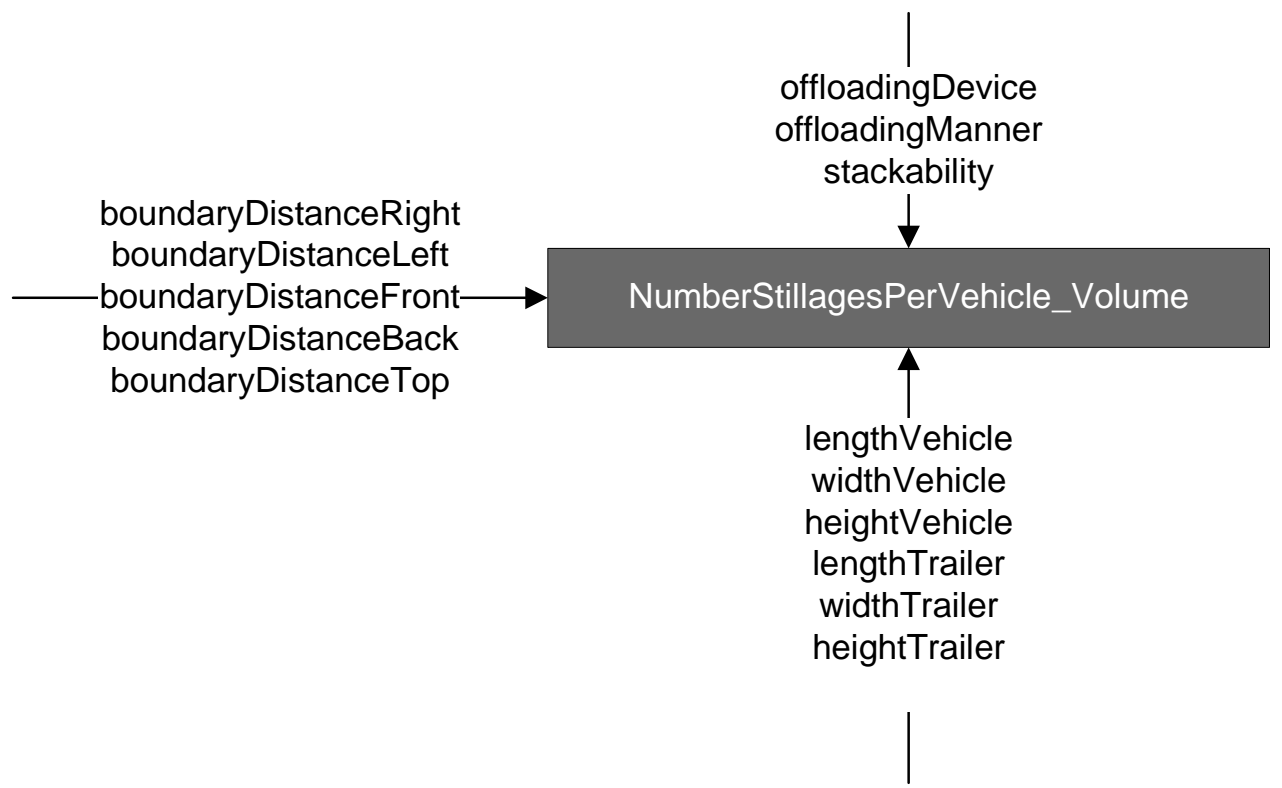

- NumberStillagesPerVehicle_Weight (as type Integer): the maximum number of stillages of a specific part family that can (theoretically) be packed on a vehicle before the vehicle reaches it's weight restriction calculated from:

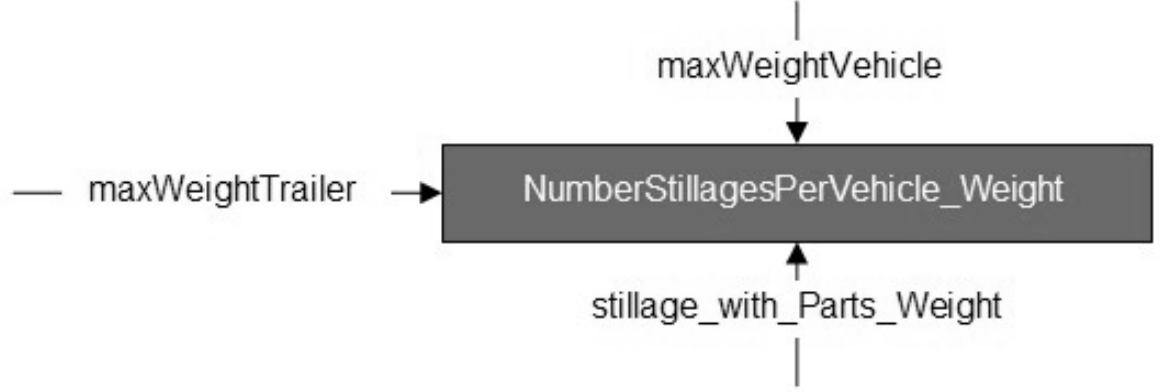

- NumberStillagesPerVehicle (as type Integer): the maximum number of stillages of a specific part family that can be packed on a vehicle calculated from: 


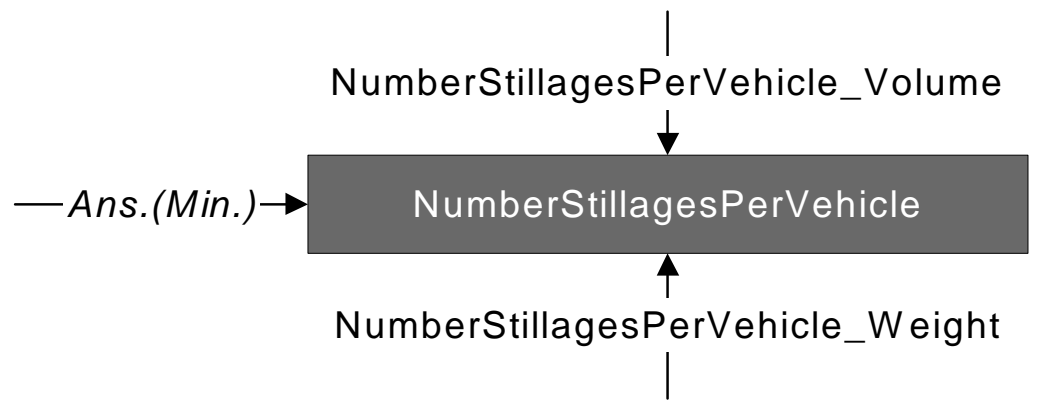

- Deliveries_required_per_day (as type Double): the number of deliveries of the specific part family required per day, calculated from:

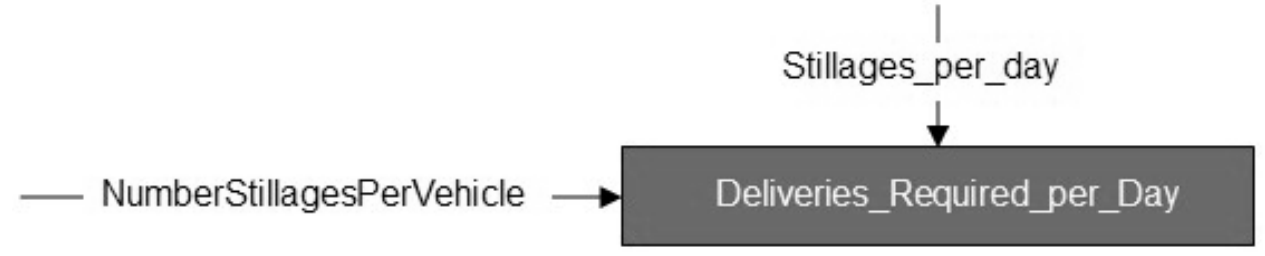

- Absolute_Deliveries_required_per_day (as type Integer): the absolute number of deliveries of the specific part family required per day, calculated from:

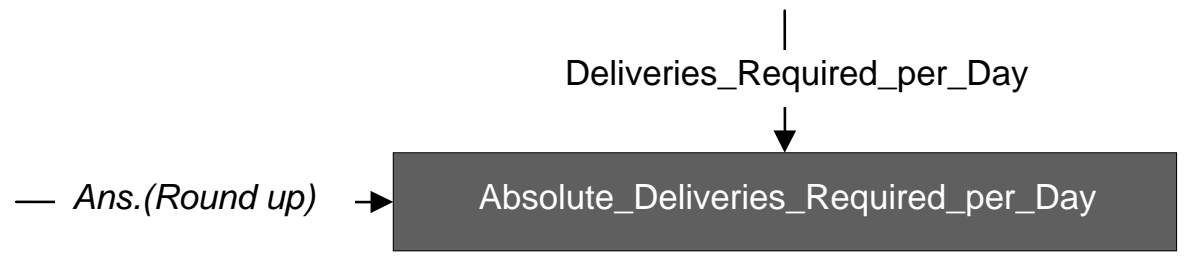

- Restcapacity_stillage_last_vehicle (as type Integer) calculated from:

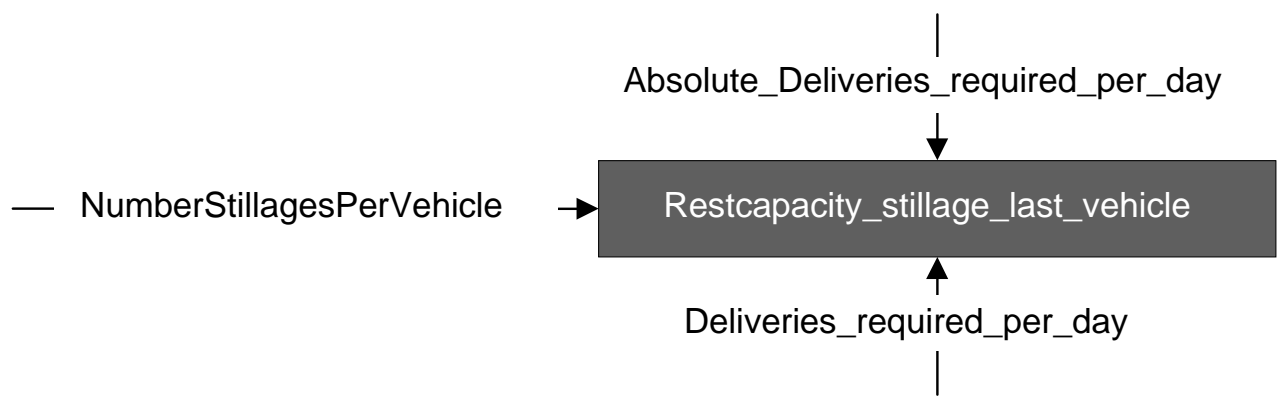

The calculation outputs are displayed on the main sheet of the tool's user interface (see Figure 1). Both the vehicle yielding the lowest number of deliveries required per day and the vehicle resulting in the lowest cost per day are automatically highlighted in the main sheet for easy identification (ref. 1 in Figure 1).

To illustrate both the sensitivity of the calculation output to parameter changes and the capability of the tool in terms of calculation speed and usage efficiency, a simple example follows: 
The output shown in Figure 1: Main Sheet clearly indicates that (for the selected part family and settings):

- both the "OP Plastic" and "KAR" vehicles are the most favourable in terms of the number of deliveries required per day (4.5 deliveries required per day, on average)

- the "Laeapple" (a delivery vehicle from one of the suppliers) vehicle is the most favourable in terms of the daily cost implication (R1450 per day, on average)

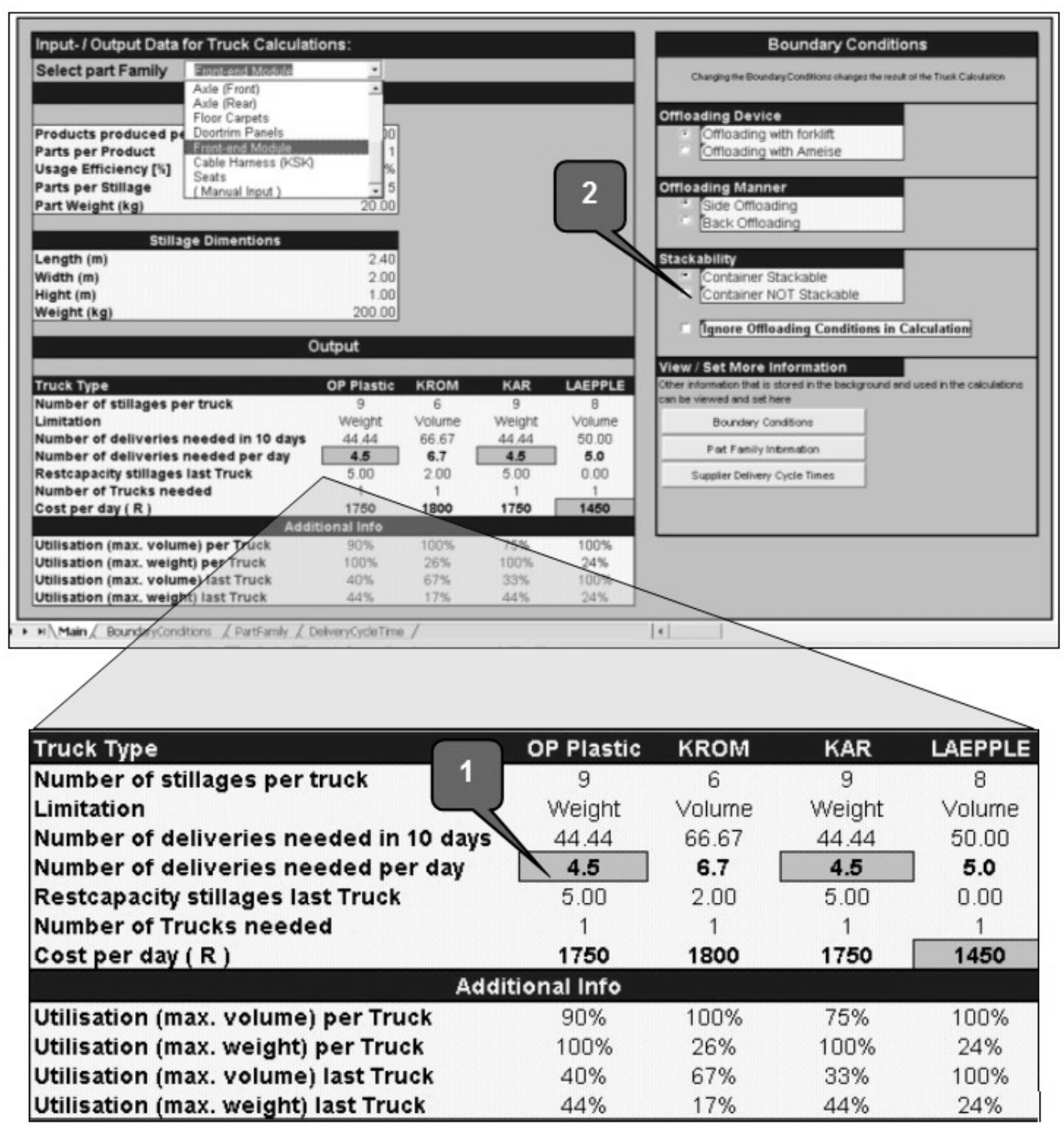

Figure 1: Main Sheet

By changing only one variable in the calculation, namely the stackability ${ }^{5}$ of the container (ref. 2 in Figure 1), the calculation output changes considerably (see Figure 2: Capability example).

\footnotetext{
${ }^{5}$ An indication of whether the stillages may be stacked on top of one another or not when packed on the delivery vehicle
} 


\begin{tabular}{|c|c|c|c|c|}
\hline Truck Type & OP Plastic & KROM & KAR & LAEPPLE \\
\hline Number of stillages per truck & 5 & 3 & 6 & 4 \\
\hline Limitation & Volume & volume & volume & Volume \\
\hline Number of deliveries needed in 10 days & 80.00 & 133.33 & 66.67 & 100.00 \\
\hline Number of deliveries needed per day & 8.0 & 13.4 & 6.7 & 10.0 \\
\hline Restcapacity stillages last Truck & 0.00 & 2.00 & 2.00 & 0.00 \\
\hline Number of Trucks needed & 1 & 2 & 1 & 2 \\
\hline Cost per day ( $R$ ) & 1750 & 3600 & 1750 & 2900 \\
\hline \multicolumn{5}{|c|}{ Additional Info } \\
\hline Utilisation (max. volume) per Truck & $100 \%$ & $100 \%$ & $100 \%$ & $100 \%$ \\
\hline Utilisation (max. weight) per Truck & $56 \%$ & $13 \%$ & $67 \%$ & $12 \%$ \\
\hline Utilisation (max. volume) last Truck & $100 \%$ & $33 \%$ & $67 \%$ & $100 \%$ \\
\hline Utilisation (max. weight) last Truck & $56 \%$ & $4 \%$ & $44 \%$ & $12 \%$ \\
\hline
\end{tabular}

Figure 2: Capability example

The calculation output now indicates that:

- the "KAR" vehicle is the most favourable in terms of the number of deliveries required per day (6.7 deliveries required per day, on average)

- both the "OP Plastic" and "KAR" vehicles are the most favourable in terms of the daily cost implication (R1750 per day, on average)

\subsection{Traffic flow simulation model}

\section{User requirements specification}

- A comprehensive traffic flow simulation model of the BMW Plant in Rosslyn is required, simulating the traffic movement within the plant boundaries but outside plant buildings - thus, traffic flow in the streets within the plant.

- The final deliverable should be a tool capable of assessing the impact of proposed changes to the plant layout, location of supplier delivery points within the plant and different supplier delivery vehicles for several part families.

- The scenario representing the current situation of the current production scenario (where the E46 models are manufactured) should initially be developed, to serve both as a means of validating the functionality and accuracy of the model and as a basis model for future scenarios. This model would have to be easily adaptable to incorporate suggested changes in the future.

- It is essential that both the model's input data and simulation results can be viewed and manipulated by users with relatively low computer skills and possibly no simulation skills, independent of the simulation model and -software.

- The generated simulation results have to be presented in a graphical, easily interpretable format in order to compare various scenarios quickly and intuitively and to communicate the results effectively across all organisational levels.

\section{Model development}

The Traffic Flow Simulation Model is a tool developed using eM-Plant simulation software. It is capable of assessing the impact of proposed changes to the plant layout, location of supplier delivery points within the plant and different supplier delivery vehicles for several part families. 
The model was constructed by first developing five intelligent building blocks. These allow the user to construct his own plant layout by simply adding the required predeveloped building blocks into the model and connecting them appropriately, almost like building a puzzle. Each time the model is initialised, changes made to the layout are automatically identified and updated in the rest of the model.

Following the user requirements, both the input data and simulation results are captured in Microsoft Excel spreadsheets. The spreadsheet format and layout are predefined and cannot be changed by the user. The user is restricted to changing the values within each "cell” within the spreadsheets only. Predefining the spreadsheet format and layout is a prerequisite for the functionality of the interface between the Excel spreadsheets and the eM-Plant model. Data transfer between Microsoft Excel and eM-Plant is enabled through eM-Plant's "activeX" interface. With every simulation run, data is first converted from the "Input_Data.xls" Excel spreadsheet into the appropriate eM-Plant tables. As the simulation run is completed, statistical data collected during the run and stored in eM-Plant tables are converted into the “Traffic_Results.xls" Excel spreadsheet. Detailed traffic profiles of the roads within the plant and statistical measures can be viewed and compared to those of other scenarios.

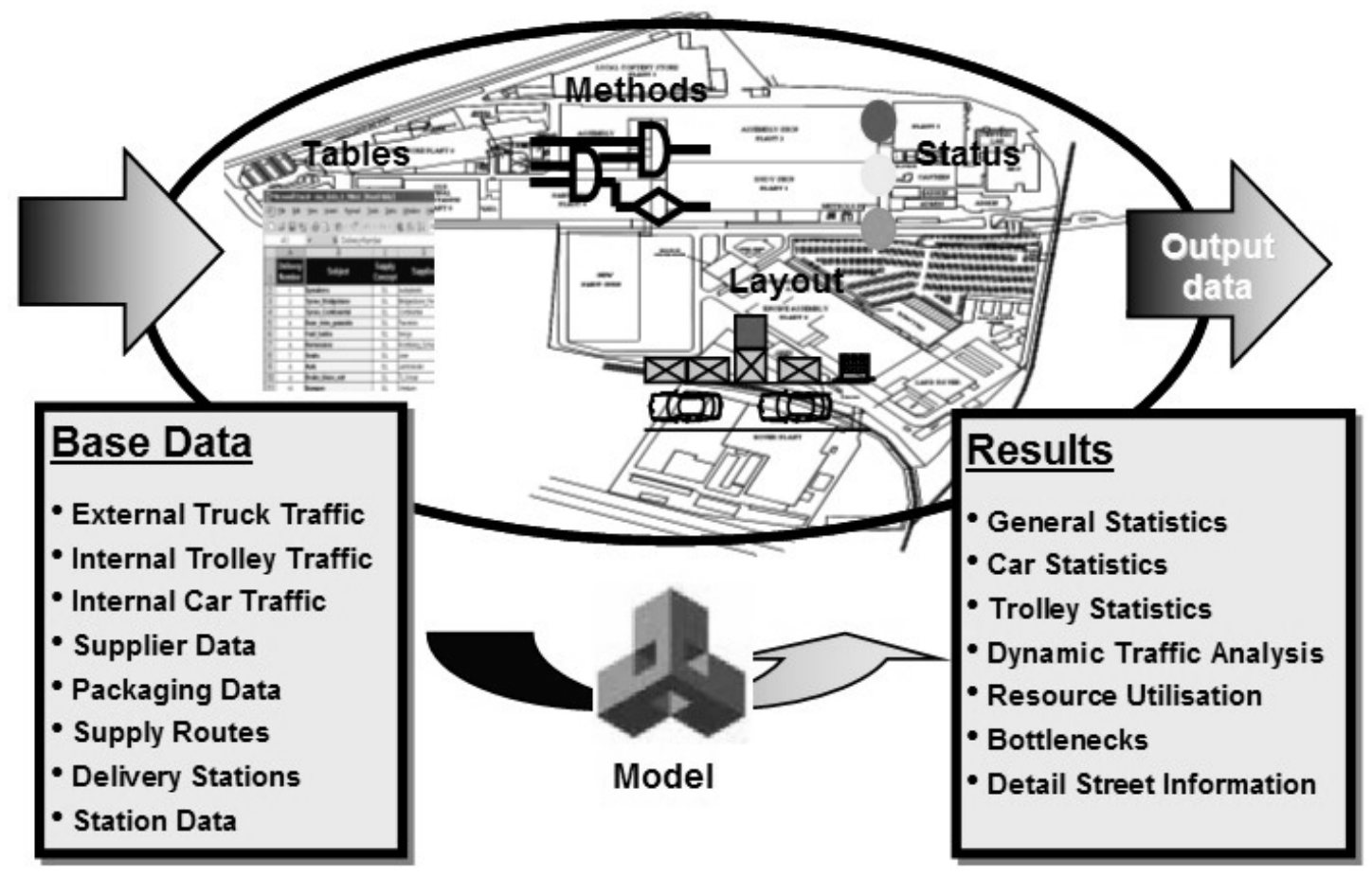

Figure 3: Traffic flow simulation concept

\section{Input data}

The following data was collected as input to the simulation model and entered into a pre-configured Excel spreadsheet: 
- All truck deliveries to the plant: A list of names of all the deliveries made to the plant by trucks (supplier delivery vehicles)

- All trolley rotations within the plant: A list of names of all the trolleys regularly moving between two stations within the plant

- All forklift rotations within the plant: A list of names of all the forklifts regularly moving between two stations within the plant

- Number of cars produced per day: The average daily production volume was calculated (taken as the average over the last 6 months of production)

- Car routing logic within the plant: A list containing all the stations within the plant that a car may have to visit, all the following stations that the car may visit from that station, as well as the probability of a car visiting a following station from its current station

- Delivery frequency of every truck delivery: The average number of deliveries per day was calculated (taken as the average over the last six months of production) for every truck delivery made to the plant

- Number of rotations per day made by every forklift and trolley: The average number of rotations made per day between the two rotation stations (taken as the average over the last six months of production) for every trolley / forklift

- Delivery route of every truck delivery: Defined by three attributes, namely the delivery's:

- Entry gate

- Delivery point

- Exit gate

- Rotation route of every trolley and forklift: Defined by the 2 stations within the plant that the trolleys / forklifts rotate between

- Plant opening hour: The time of day that the first production shift starts within the plant

- Plant closing hour: The time of day that the last production shift ends within the plant

- Plant warm-up period: The period of time between the plant opening time and the time the gates are opened to receive truck deliveries to the plant

- Plant cool-down period: The period of time between the time that the gates are closed to truck deliveries to the plant and the plant closing time

Other data and information was also collected to assist model development. This included:

- Plant layout: Information about the location of all gates and delivery points within the plant

- Properties of all roads within the plant: (length, width, one/two directional, speed restrictions)

- Properties of all delivery points / stations within the plant: (number of marshalling zones per station, number of buffer places per station, operating schedule per station) 


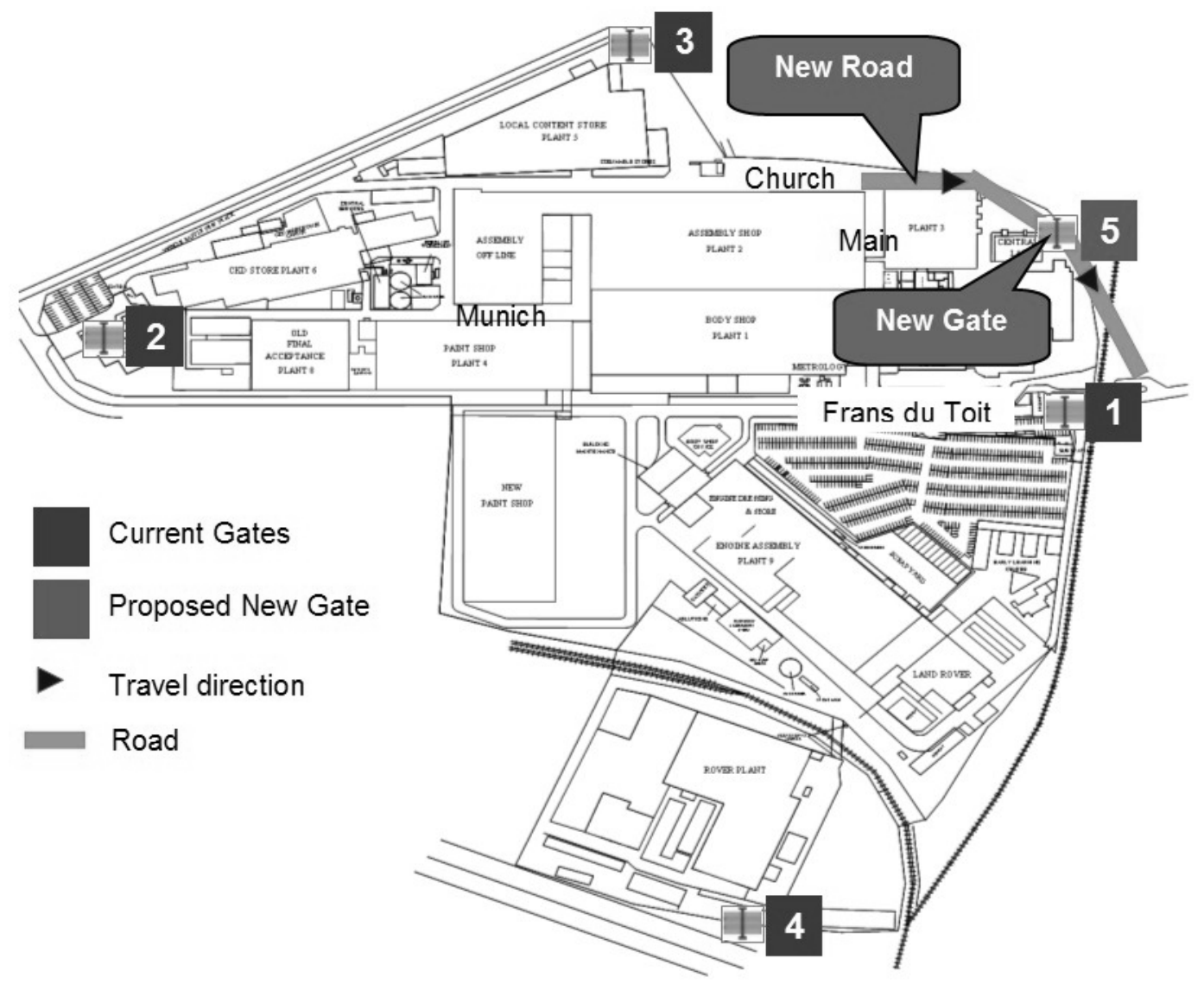

Figure 4: New road- and gate construction

\section{Verification and validation}

The model was verified and validated by:

- Doing a "walk through" of the entire model, verifying that it operates in the intended manner according to the modeling assumptions made and programming logic used

- Verifying the validity of all assumptions made during the modeling process

- Comparing the simulation results with actual information and performing hypothesis tests to ensure that the model accurately represents reality

\section{Model application}

To illustrate the capability and use of the tools developed during this project, both the current scenario at BMW Plant 9 in Rosslyn as well as one of the major changes considered within the plant was evaluated and compared to the current scenario.

\section{Scenario}

There are currently four gates at BMW Plant 9 through which vehicles enter and exit the plant. One of the structural changes considered in preparation of the production 
of the E90 (new 3 series) is the introduction of a new gate, which will be named "Gate 5" (see Figure 4). This gate will be located in the north-east side of the plant, and is expected to reduce traffic levels in both Main- and Church street, two of the (current) critical traffic flow areas within the plant.

The introduction of this gate will imply large expenses, like the:

- initial investment cost of constructing the new gate

- initial investment cost of building a new road stretching from Church street to the new gate, and from the new gate to Frans du Toit street outside the plant (see Figure 4)

- running cost of additional security personnel to man the new gate

\begin{tabular}{|l|c|c|}
\hline General Statistics & \multicolumn{2}{|c|}{ Scenario } \\
\hline \# Trucks & Base & New Gate 5 \\
\hline \# Trolley (Rotations) & 246.90 & 246.75 \\
\hline \# Cars (left the Plant) & 240.20 & 238.40 \\
\hline
\end{tabular}

\begin{tabular}{|l|c|c|}
\hline Car Statistics & \multicolumn{2}{c|}{ Scenario } \\
\hline Max Process Time & $06: 09: 40$ & NewGate 5 \\
\hline Ave Process Time & $02: 06: 50$ & $06: 13: 00$ \\
\hline Max Driven Km & 8.06 & $02: 06: 10$ \\
\hline Ave Driven Km & 1.94 & 7.44 \\
\hline
\end{tabular}

\begin{tabular}{|l|c|c|}
\hline Trolley Statistics & \multicolumn{2}{c|}{ Scenario } \\
\hline Max Supply Route (All) Km & 16.39 & 16.47 \\
\hline Ave Supply Route (All) Km & 7.65 & 7.68 \\
\hline Max Supply Route (Single) & 2.22 & 2.26 \\
\hline Ave Supply Route (Single) & 1.21 & 1.23 \\
\hline
\end{tabular}

\begin{tabular}{|l|c|c|}
\hline Truck Statistics & \multicolumn{2}{c|}{ Scenario } \\
\hline Max Process Time & $01: 57: 14$ & Nase \\
\hline Ave Process Time & $00: 30: 13$ & $01: 55: 34$ \\
\hline
\end{tabular}

\begin{tabular}{|l|c|c|}
\hline Max Driven Km & 1.22 & 1.24 \\
\hline Ave Driven Km & 0.74 & 0.75 \\
\hline
\end{tabular}

Table 1: Comparing Base- and New Gate 5 Scenarios

The new gate and road are planned to be used as a means for trucks to exit the plant only (vehicles will not enter the plant through the new gate), creating a general flow of traffic in Church and Main street towards the new gate.

The impact that the new gate is expected to have on the overall plant traffic could previously only be speculated upon. By utilising the tools developed during this 
project, the expected impact can be evaluated and quantitatively compared to the current scenario.
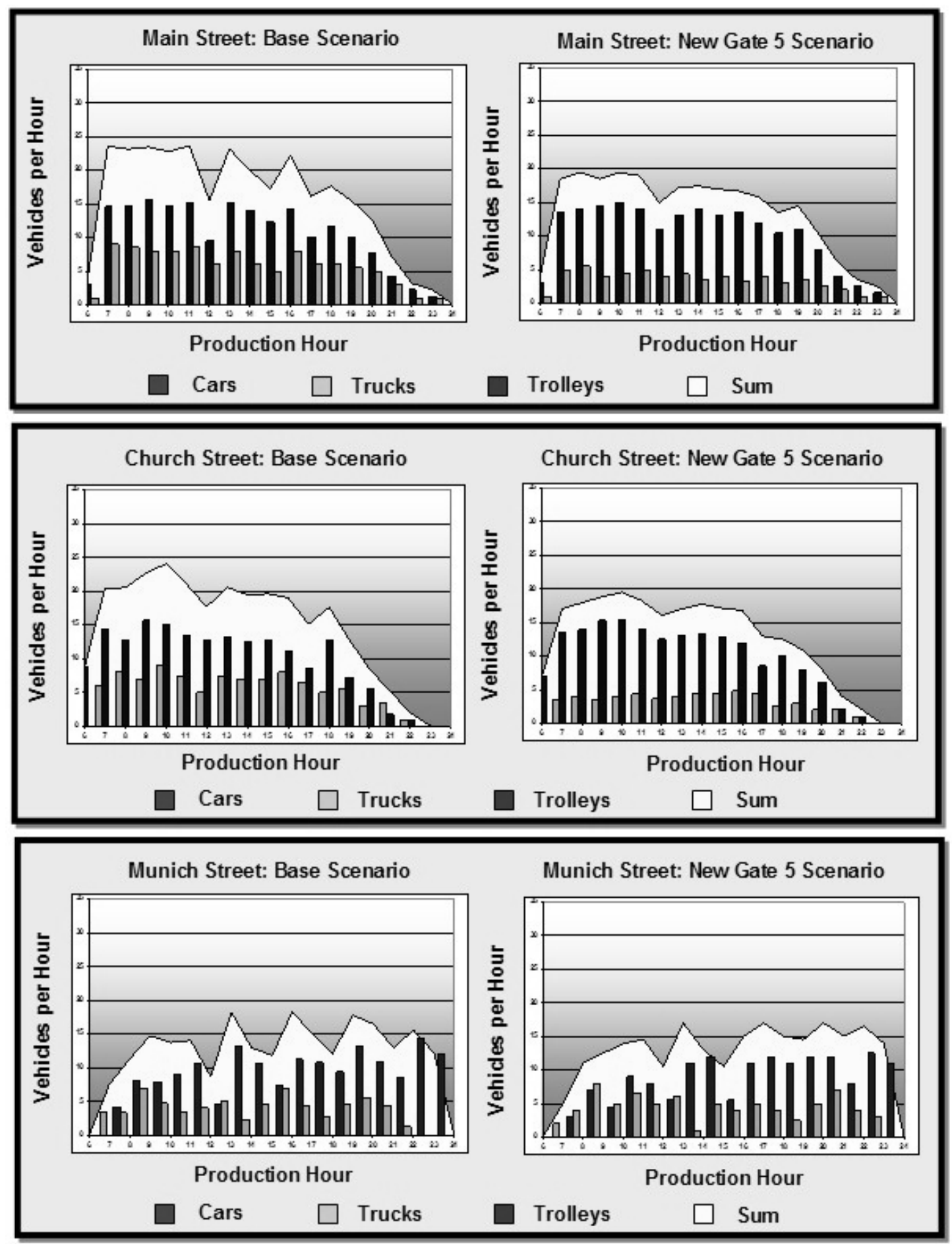

Figure 5: Comparing simulation results

The model should now be adapted by simply adding the additional pre-developed gate- and roads building blocks to the current model's layout and connecting them appropriately, almost like building a puzzle. The route information of all vehicles 
that are to use gate 5 (the new gate) as an exit gate should also be updated accordingly in the input data file. As the model is initialised, all changes will automatically be identified and updated in the rest of the model.

\section{Comparing results}

After running the New Gate 5 scenario, it's simulation results are compared to that of the base scenario (see Figure 5 and Table 1).

The results clearly show an expected reduction in the traffic levels in Main- and Church street, but no substantial change to the traffic levels in Munich street. Intuitively, this is exactly the results that would be expected for the New Gate 5 scenario, since:

- A considerable portion of the traffic would be directed towards the new street and -gate, relieving some of the traffic in the nearby streets.

- Traffic-flow in Munich street will not be affected by the changes proposed for the New Gate 5 scenario, as all of the vehicles moving in Munich street enter and exit the plant through gate 2 .

Since the cost of constructing the new gate and road has already been determined, an informed decision can now be made by BMW Plant 9's management on whether this proposed scenario should be implemented or not.

\section{CONCLUSION}

The effects of various decisions considered during the supply planning process and the impact of these decisions on plant traffic can now be systematically evaluated (see Figure 6).

- Firstly: by means of the SMDST, which provides critical information about the cost implication and number of deliveries required for all possible combinations of part families and delivery vehicles used

- Secondly: the simulation model's input data file can easily be updated in accordance with the SMDST's information in preparation of a new simulation experiment

- Thirdly: the traffic flow simulation model can be run. The model will automatically use the updated input data file and create unique results files for the scenario currently under analysis

- Fourthly: the simulation model's results files can be viewed and compared to those of previous scenarios

Every component of the DSS was developed generically as far as possible, allowing the user to adapt it to other similar manufacturing environments with relative ease by adding / removing the pre-developed intelligent building blocks (see 3.2 Traffic Flow Simulation Model). Although initially developed for application in the automotive manufacturing environment, the DSS now finds application in other manufacturing environments (e.g. mining industry, component manufacturing and consumable goods production). 
By utilising the DSS, the effects of various decisions considered during the supply planning process and the impact of these decisions on plant traffic can be evaluated and compared rapidly and more efficiently by means of more quantitative measures than before, considerably reducing uncertainty and risk of planning. This system undoubtedly supports automotive manufacturers in their quest for manufacturing excellence in an ever-increasing internationally competitive and complex environment.

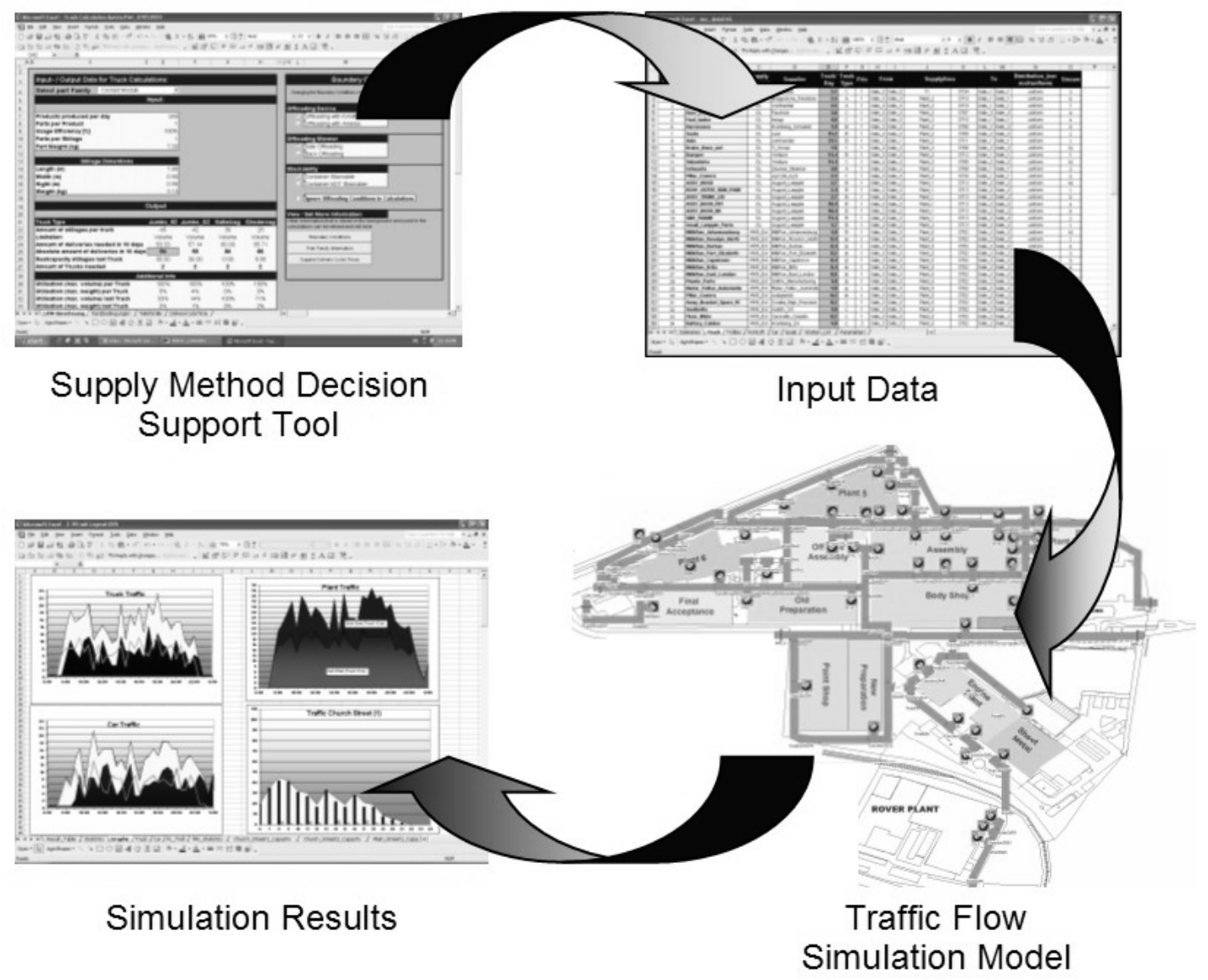

Figure 6: Overview of supply and traffic flow Decision Support System (DSS)

\section{REFERENCES}

[1] Alter, S.L., Decision Support Systems: Current Practices and Continuing Challenges. Reading, MA: Addison-Wesley, 1980

[2] Anderson, D, Beyond change management, Pfeiffer, 2001

[3] Baron, R.A., Byrne, D., Social Psychology: Understanding Human Interaction, seventh edition, Boston: Allyn and Bacon, 1994

[4] Davis, D., Business Research for Decision Making, fifth edition, Duxbury, 2000

[5] Fitzpatrick, J., Secrist, J., Wright, D. J., Secrets for a successful dissertation, Sage Publications, 1998 
[6] Gogg, T. J., Mott, J. R. A., Improve quality and productivity with simulation, 1992

[7] Harrington, H. J., Tumay, K., Simulation Modeling Methods, McGrawHill, 2000

[8] Hesse, R., Managerial spreadsheet modeling and analysis, Irwin, 1997

[9] Hultman, K., Making change irresistible : overcoming resistance to change in your organization, Davies-Black, 1998

[10] Johnson, R. A., Miller and Freud's Probability and Statistics for Engineers, fifth edition, Prentice-Hall, 1994

[11] Judson, A. S., Changing behavior in organizations : minimizing resistance to change, Blackwell Business, 1991

[12] Keen, P.G.W., and M.S. Scott-Morton. Decision Support Systems, An Organizational Perspective. Reading, MA: Addison-Wesley, 1978

[13] Kelton, W. D., Sadowski, R. P., Sadowski, D. A., Simulation with Arena, p.176, 1998

[14] Kerlinger, F. N., Foundations of Behavior Research, third edition, New York, 1986, p.10

[15] Krick, E., An Introduction To Engineering Concepts, Methods And Issues, New York, John Wiley \& Sons, Inc., 1974

[16] Louw, D.A., Human Development, Pretoria: HAUM, 1991

[17] McLeod, J., Simulation, Volume 51, Number 4, October, Simulation Councils, Inc., 1988

[18] Melville S, Goddard W, Research Methodology, Juta \& Co Ltd, 1996

[19] Mouton, J., How to succeed in your Master's and Doctoral Studies, Van Schaik, 2001

[20] Oxford, The Oxford Encyclopaedic English Dictionary, Oxford University Press, New York, 1991

[21] Sage, A.P., Decision Support Systems Engineering, John Wiley \& Sons, Inc. 1991

[22] Schneidman, B., Designing the User Interface: Strategies for Effective Human Computer Interface, Addison-Wesley, Reading, MA, 1987

[23] Simon, H. The New Science of Management Decision. Englewood Cliffs, NJ: Prentice-Hall, 1977

[24] Sprague, R. H., Jr., Watson H. J., Decision Support Systems: Putting Theory into Practice, Prentice-Hall, 1993

[25] Swain, J. J., "Imagine New Worlds" OR/MS Today, February 1999, pp. 3841

[26] Turban, E. Decision support and Expert Systems: Management Support Systems, third edition, Macmillan, 1993

[27] Whicker, M. J., Sigelman, L., Computer Simulation Applications: An Introduction, Sage Publications, 1991

[28] Zikmund, W. G., Business Research Methods, South-Western, 2003

[29] www.sei.cmu.edu 